\title{
O fenômeno migratório nos mapas: o que se fixa dos discursos sobre a humanidade em fluxo?
}

\author{
The migratory phenomenon on maps: what is fixed from speech about \\ humanity in flow?
}

\section{Diego Martins da Cruz'}

\section{RESUMO}

À medida que a intensidade do fluxo migratório cresce e tensiona a União Europeia, sobretudo nas ultimas décadas, crescem em igual medida os esforços pelo controle de fronteiras (Frontex) e imprensa internacional de sua leitura e monitoramento. O resultado destes esforços é traduzido e reportado, com uso da linguagem cartográfica, ao cidadão europeu em uma lógica de prestação de contas acerca da contenção destes fluxos por meio da representação que deles é construída. Não raro, são estes mapas que subsidiam o ensino de geografia nas escolas. Esse artigo se propõe a analisar o discurso presente em mapas temáticos produzidos por órgãos oficiais europeus, suas possíveis implicações ideológicas e indicar possíveis alternativas para o estudo destes fenômenos espaciais no ensino de geografia. Os referenciais teóricos para essa análise estão presentes no campo da Análise do Discurso, da Cartografia Crítica e aprendizagem por investigação.

Palavras-chave: Cartografia critica; Coremas; Ensino de geografia; Mapas; Migração

\section{ABSTRACT}

As the intensity of the migratory flow grows and tenses the European Union, especially in recent decades, so have the efforts of border control (Frontex) and the international press to read and monitor them. The result of these efforts is translated and reported, using cartographic language, to the European citizen in a logic of accountability regarding the containment of these flows through the representation that is constructed from them. Not infrequently, these maps support the teaching of geography in schools. This article aims to analyze the discourse present in thematic maps produced by European official bodies, their possible ideological implications and to indicate possible alternatives for the study of these spatial phenomena in the teaching of geography. The theoretical references for this analysis are present in the field of Discourse Analysis, Critical Cartography and learning by investigation.

Keywords:_Critical Cartography; Choremas; Geography Teaching; Maps; Migration

Mestrando no programa de pós graduação em Geografia da UFMG E-mail: diegomartins23@yahoo.com.br ORCID: https://orcid.org/0000-0003-0615-6981 


\section{CONSIDERAÇÕES INICIAIS}

Os mapas possuem certo caráter de convencimento sobre a realidade que não deve ser minimizado e historicamente tem se constituído objetos valorizados enquanto representações efetivas do espaço (DEL GAUDIO, 2003). Este estudo parte da premissa que os mapas portam discursos sobre o território. A imagem de uma suposta "neutralidade" atende a diversos interesses, dentre os quais aqueles relacionados a veículos de informação que usam dessa linguagem para vender imparcialidade quando repercutem sobre os fenômenos humanos. Contudo, mesmo esses veículos não estão imunes a ideologias subjacentes.

$\mathrm{Na}$ pratica diferentes ideologias coexistem e se emaranham. A determinação da relação entre dadas ideologias segundo Therborn (1999) seria de competição pelo controle da narrativa a partir do êxito interpelativo que, segundo o autor, é um processo duplo que submete e qualifica as subjetividades. É desta compreensão da noção de ideologia, fundamentada na interpelação dos seres humanos como sujeitos que este estudo se assenta. As ideologias sujeitam e qualificam as pessoas ao dizer-Ihes e fazer-Ihes reconhecer o que existe, o que é bom e o que é possível (THERBORN, 1999).

Os mapas podem se constituir mecanismos de interpelação à medida que apresentam informações codificadas, que se dirigem de um sujeito a outro o que os tornam, portanto, uma "enunciação" (Del Gaudio, 2003 p. 131) acerca de algo. Como nos lembra Lacoste (1997) a confecção de um mapa implica num certo domínio político e matemático do espaço representado, e certamente, se constitui um instrumento de poder sobre esse espaço e sobre as pessoas que ali vivem. O controle metódico e técnico dos códigos que a produção de um mapa permite a grupos específicos construir a imagem que se deseja fixar com determinada representação. Isso por que em parte, "esse poder do mapa deriva de três coisas: poucos sabem utilizá-lo efetivamente; poucos são os que os 
elaboram; são utilizados apenas determinados mapas em determinadas escalas, conforme o objetivo previamente estabelecido" (Del Gaudio, 2003 p.137).

Analogamente a fotografia, o mapa congela um momento da realidade e em igual medida também recorta o todo. Perde-se a visão periférica quando se submete a complexidade do real a um enquadramento, que equaciona um fragmento do espaço, conforme aquilo que se considera relevante de dado recorte espacial. Com isso é transmitida a sensação de que a realidade é perene, estável, não sujeita a alterações e, portanto eterna, imagem esta que desconsidera os processos históricos, sociais e econômicos, bem como as possibilidades da permanente construção/desintegração do real. O mapa seria, então:

(...) uma construção seletiva e representativa que implica o uso de símbolos e de sinais. (...) O número e o acúmulo dos símbolos dependem, com efeito, do espaço disponível: quanto maior a redução da imagem terrestre (ou seja, quanto menor for a escala), mais severa é a seleção e mais abstrata a simbologia (JOLY, 1990 p.7).

Nesse sentido Fourez (2008) adverte que um mapa não é neutro, mas sim fruto de uma seleção de elementos julgados significativos e que são portanto, mantidos. Essa seleção se faz em função de certos interesses. "Os mapas examinados são criações de culturas que percebem o espaço físico, terrestre, de maneiras diferentes, e essas percepções se refletem nos mapas que fazem" (2014, p.21). E complementa: “O mapa, seja qual for seu meio ou sua mensagem, é sempre uma interpretação criativa do espaço que afirma representar" (Fourez, 2008, p.22).

Para além desses aspectos, para retratar relacionamentos significativos de um mundo complexo e tridimensional em uma folha plana de papel ou em uma tela de vídeo, um mapa precisa necessariamente distorcer a realidade. Como representação em escala, o mapa precisa usar símbolos que quase sempre são proporcionalmente muito maiores ou mais grossos do que as características que eles representam. Para evitar esconder informações fundamentais em uma 
nuvem de detalhes, o mapa deve oferecer uma seletiva visão incompleta da realidade conforme as regras da semiologia gráfica. “Não há escapatória do paradoxo cartográfico: para apresentar uma imagem útil e fidedigna, um mapa preciso tem que contar pequenas mentiras" (MONMONIER, 1996, p.1).

É preciso não perder de vista também que mapas são elaborados para fins específicos, como os militares, estratégicos, escolares, e que sua acessibilidade e compreensão também se relacionam aos fins para os quais foram elaborados.

Portanto, um mapa é algo que se produz - representa - para alguém, que está codificado e que se pressupõe que o outro compreenda e decodifique. E que mantém a particularidade de ser o resultado de operações matemáticas e empíricas que constituem objeto de escolha de quem encomendou sua realização e de quem o materializou. Portanto, é um discurso na medida em que estabelece uma comunicação, pretende representar o espaço/território, é objeto de escolha - tanto do tema, quanto da forma - e pressupõe, mesmo durante sua elaboração, o uso e a compreensão (DEL GAUDIO, 2003 p.134).

Segundo Gérard Fourez (2008) representações podem ser utilizadas, pelo menos, de três formas: a) Como um espelho da realidade (uma perspectiva muito comum quando se trata da forma como a maioria das pessoas observa um mapa); b) Como um sinônimo de senso comum ou opinião não abalizada; c) Como algo que pode tomar o lugar da realidade em um determinado contexto. É dessa última premissa que pretendemos explorar mais neste estudo ao se pensar nas possibilidades do mapa como forma de representação.

É certo que os mapas são representações oriundas de construções matemáticas e empíricas e que, de fato, constituem uma síntese sobre o espaço. Servem fundamentalmente para fixar determinadas imagens dos territórios, reforçar certas noções de proximidade/distância aprioristicamente. Brotton (2014, p.16), nos fala acerca da "genialidade dissimuladora dos mapas" que faz com que os observadores acreditem que a perspectiva que estão vendo é verdadeira, como se eles mesmos estivessem olhando o território do alto.

A chamada cartografia crítica admite que os mapas produzem a realidade tanto quanto a representam. Talvez John Pickles o expresse melhor quando 
afirma: “Em vez de procurar como podemos mapear o objeto... [poderíamos] nos preocupar com os meios pelos quais o mapeamento e o olhar cartográfico codificaram objetos e produziram identidades (Pickles 2004 p. 12)." Segundo Lefebvre (1976), a representação do espaço (dentre elas o mapa) é um dos três elementos a partir dos quais a sociedade produz o espaço. Assim, ao assumir o mapa como parte do seu discurso, o geógrafo amplia sua capacidade de produzir o espaço ou de compreender esse produto.

Portanto, mesmo sendo também um objeto técnico, o mapa é sempre elaborado através de escolhas, as quais, ainda que tecnicamente fundamentadas, transformam-no inexoravelmente em uma narrativa do espaço. O que se buscará perscrutar ao longo deste artigo são possíveis narrativas acerca de fenômenos migratórios internacionais, a partir da linguagem dos mapas em pequena escala bem como suas implicações para a educação geográfica e formação do senso comum. Ao final será feita uma reflexão propositiva sobre possibilidades de abordagem alternativas ao cenário identificado.

\section{REPRESENTAÇÕES DOS FLUXOS MIGRATÓRIOS DO CONTINENTE EUROPEU, ALGUMAS QUESTÕES:}

Fluxos migratórios sempre foram uma constante no continente europeu (figura 1). Contudo a oscilação do fluxo, após os conflitos na Síria se intensificarem, sobretudo a partir de 2014, possibilitou a construção da percepção de uma crise incontrolável pela União Europeia e mídia internacional. Desse modo, as migrações humanas e a xenofobia tiveram grande influência nas eleições realizadas desde então na Áustria, França, Alemanha, Itália e outros países europeus com crescimento de partidos populistas eurocéticos ligados a ultra direita conservadora. 
Figura 1- Oscilação dos fluxos migratórios do período de 1986 até 2014 com marcos referenciais no inicio dos conflitos da Iugoslávia, Guerra do Kosovo e Guerra na Síria respectivamente.

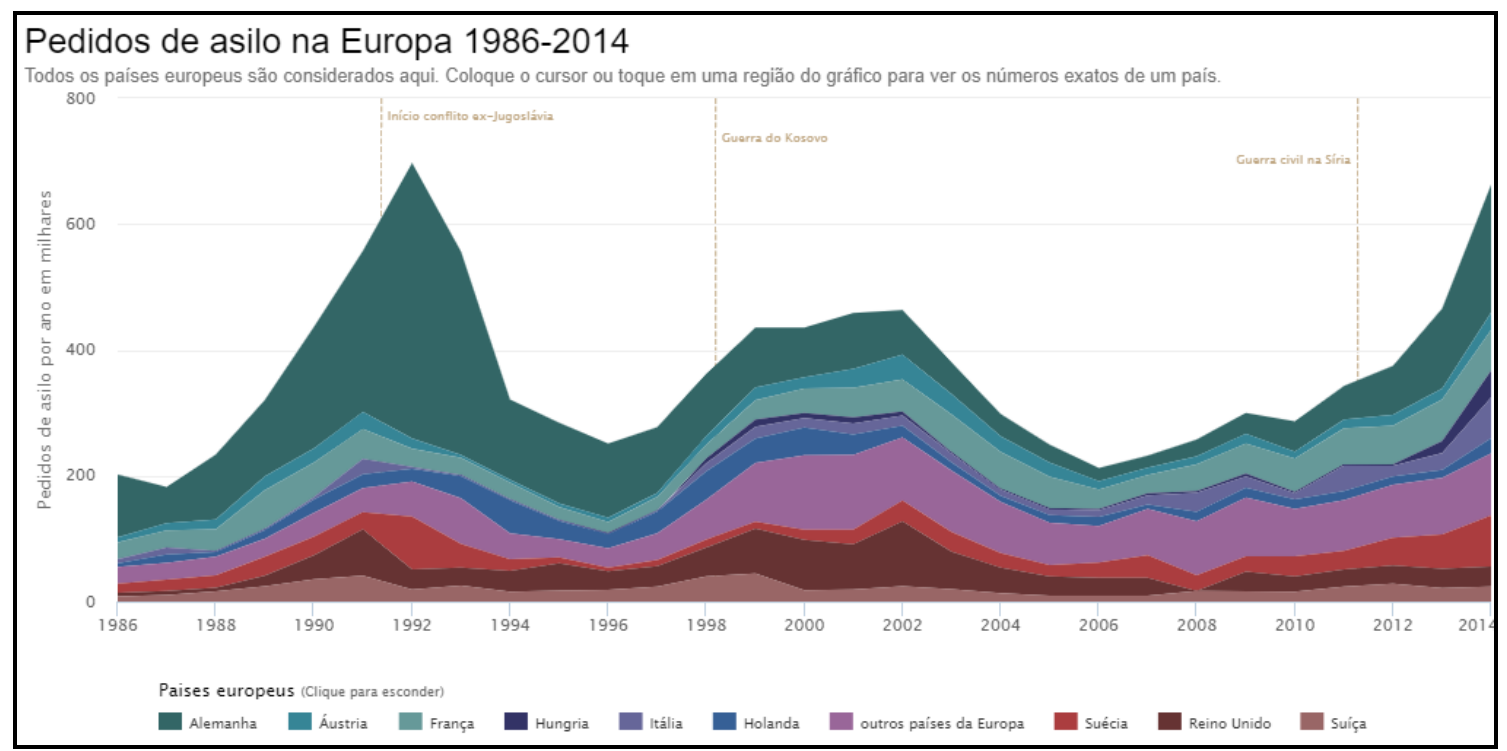

Fonte: $\quad$ https://www.swissinfo.ch/por/politica/a-loteria-do-asilo seis-gr\%C3\%A1ficos-ilustrammelhor-o-fen\%C3\%B4meno-migrat\%C3\%B3rio/41557156 Acessado em: 01/2019.

Até essa nova oscilação em 2014 a Europa apresentava relativa abertura de fronteiras. A partir de então se estabelece um esforço para impedir a chegada do fluxo massivo de migrantes que fugiam, sobretudo, da guerra civil na Síria e de outros conflitos que a antecedem mas com consequências em curso, como os do Iraque e Afeganistão.

Observou-se na ultima década, uma corrida pelo recrudescimento das fronteiras, em um primeiro momento, nas dependências dos próprios estados membros e, posteriormente, via acordos diplomáticos em países que se constituíram "zonas tampões" para interceptar os fluxos já em suas principais rotas. Foi o caso da Turquia, Grécia e alguns países africanos como Níger, Líbia e Tunísia i(figura 2).

Figura 2- Externalização dos controles de fronteira para além dos limites da união europeia. 


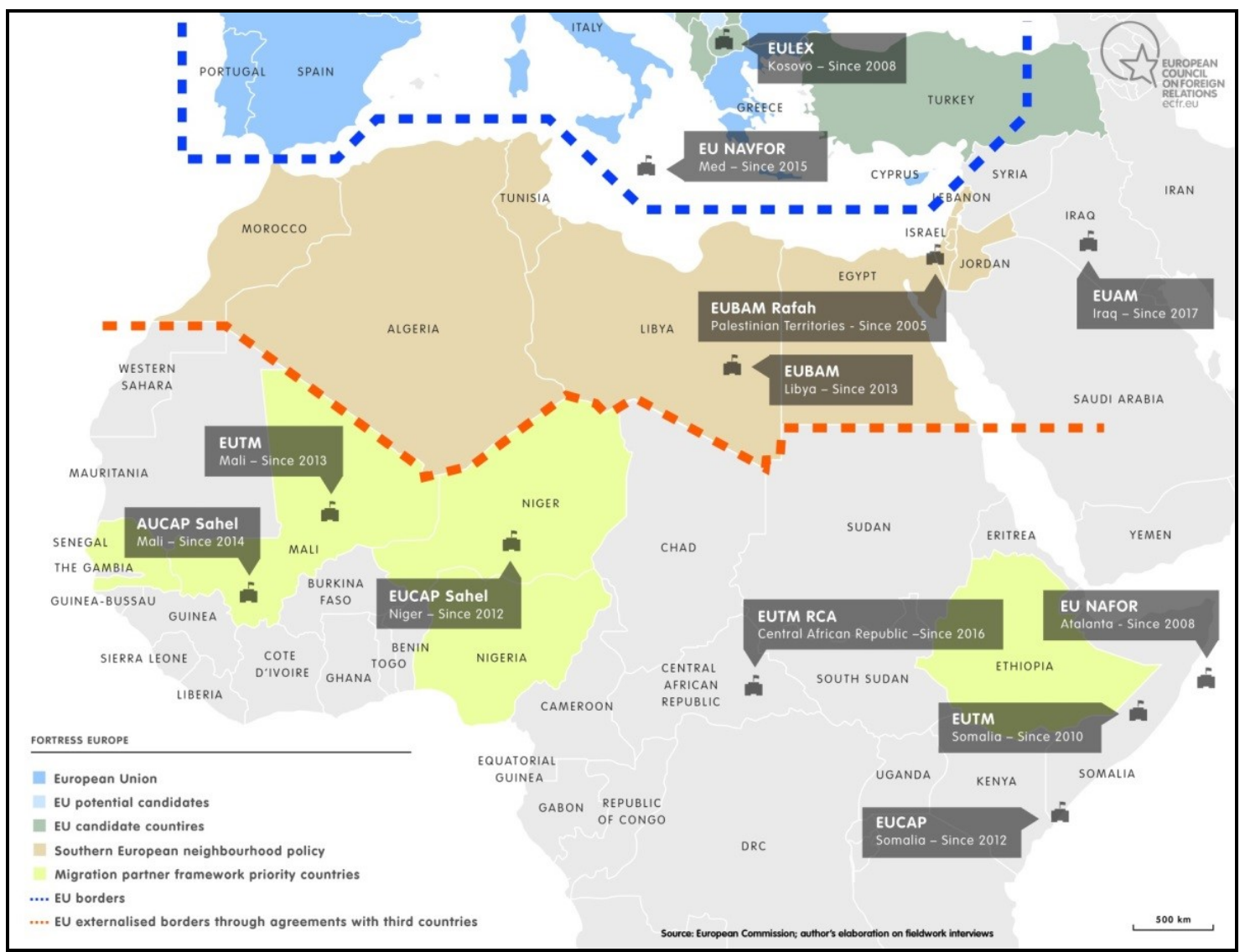

Fonte: Disponível em: https://www.washingtonpost.com/graphics/world/border-barriers/europerefugee-crisis-border-control/?noredirect=on Acessado em 01/2019.

A Frontex, a Agência Europeia da Guarda de Fronteiras e Costeira, foi criada em 2004 para ajudar os estados membros da União Europeia e os países associados ao Schengen para proteger as fronteiras do espaço de livre circulação. Com a intensificação dos fluxos migratórios entre 2014 e 2015, teve seu escopo de atuação expandido para o controle da migração e “operações de busca e salvamento". Segundo a própria agencia sua missão é "Proteger o espaço europeu e garantir a liberdade, segurança e justiça". ii

Os dados registrados em seu monitoramento (figura 3), recorrentemente são citados como as bases de todo material infográfico utilizado pela grande mídia, para informar aos europeus e ao mundo um "retrato" da conjuntura deste fenômeno migratório e o que tem sido feito para seu controle.

O simples ato de informar interpela os sujeitos a fixar determinadas imagens sobre os fluxos migratórios no imaginário popular, que podem 
consolidar estereótipos e trazer implicações sociopolíticas. Aspecto que este estudo pretende analisar.

Figura 3- "Migratory Map": mapa interativo na qual cada círculo representa as principais rotas de migração para Europa. Informações como direção, titulo e legenda não estavam disponíveis na versão interativa do mapa de interface da ESRIArc Gis.

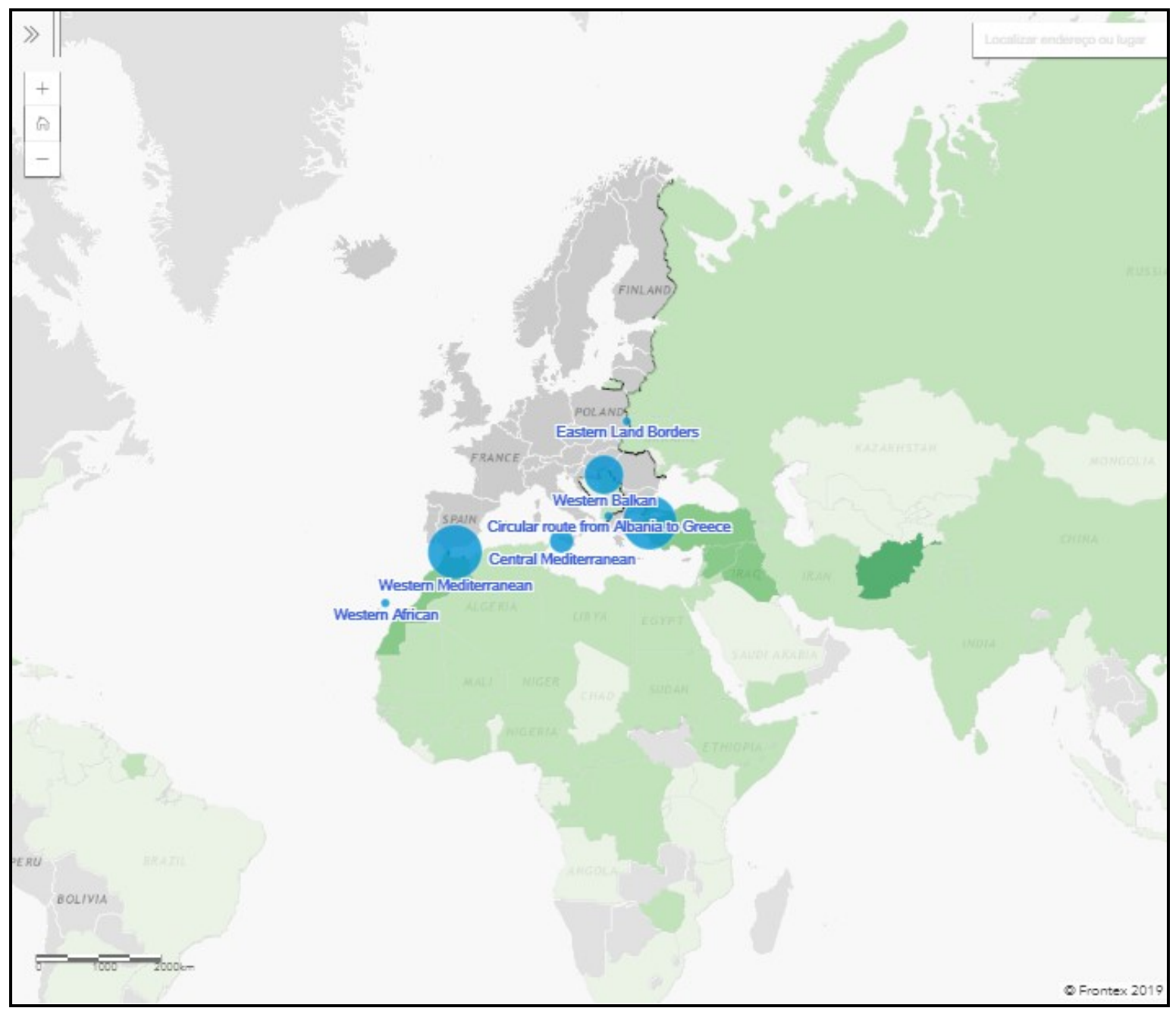

Fonte: Disponível em: https://frontex.europa.eu/along-eu-borders/migratory-map/ Acessado em 04/04/2019.

Os dados da Frontex costumam ser a fonte primaria recorrente para materiais cartográficos e infográficos que são produzidos sobre o continente europeu. Neles são destacados os principais países de origem dos fluxos, identificados pela gradação da cor verde, e a interceptação destes imigrantes na fronteira. Há, portanto, uma lógica de prestação de contas sobre a atuação da 
agencia que visa destacar quem são os barrados e quantos são. Assim como ocorre em mapas de pequena escala, este traz suas generalizações e seleciona as informações que julga mais importantes comunicar, sobretudo aos membros da união europeia, uma imagem de proteção. Essa imagem que vem sendo construída tem sido denominada por analistas de "Fortaleza Europa".

Demais aspectos envolvidos que poderiam tecer novos e outros entendimentos não são demarcados, tais como o fato de que parte desta retenção assinalada pelos círculos concêntricos de azul são óbitos. Outros elementos como os fatores de repulsão que impulsionam os fluxos e sua natureza são silenciados, assim como as principais rotas e seus pontos de atração. O quantitativo de imigrantes que conseguem adentrar ao espaço europeu com êxito, bem como seu perfil ou qualificação, que poderiam ser indicativos dos critérios de triagem são outros dados que não aparecem. As escolhas visuais invisibilizam acima de tudo os centros de triagem, que tem se consolidado como verdadeiros campos de concentração de refugiados e imigrantes econômicos além de suas condições de operação.

O que importa é garantir e fixar a imagem de que a "liberdade, segurança e justiça" dos países membros esteja protegida, consolidando assim o supracitado cenário de “Fortaleza Europa". Essa função criadora/reforçadora de identidades é poderosa em mapas posto que contem toda uma propaganda ideológica, política, cultural e econômica. Como definiu Althusser, "a ideologia é uma representação da relação imaginária dos indivíduos com suas condições reais de existência" (Althusser, 1996 p.126) quando delas se consegue aproximar.

A cobertura midiática dos fluxos migratórios sobre o continente europeu, que verificou auge de intensidade em 2015, foi discrepante quando comparada a cobertura de outros do mesmo períodoiii. O curioso é que o fluxo migratório para o continente europeu foi proporcionalmente inferior quando comparado a outros em um mesmo período (figura 4). Isso sinaliza uma preocupação de caráter 
obtuso, cujas razões não estão bem demarcadas, acerca da construção de entendimentos sobre este fenômeno migratório em especifico.

Figura 4- Numero de imigrantes internacionais classificados por região de origem e destino.2017

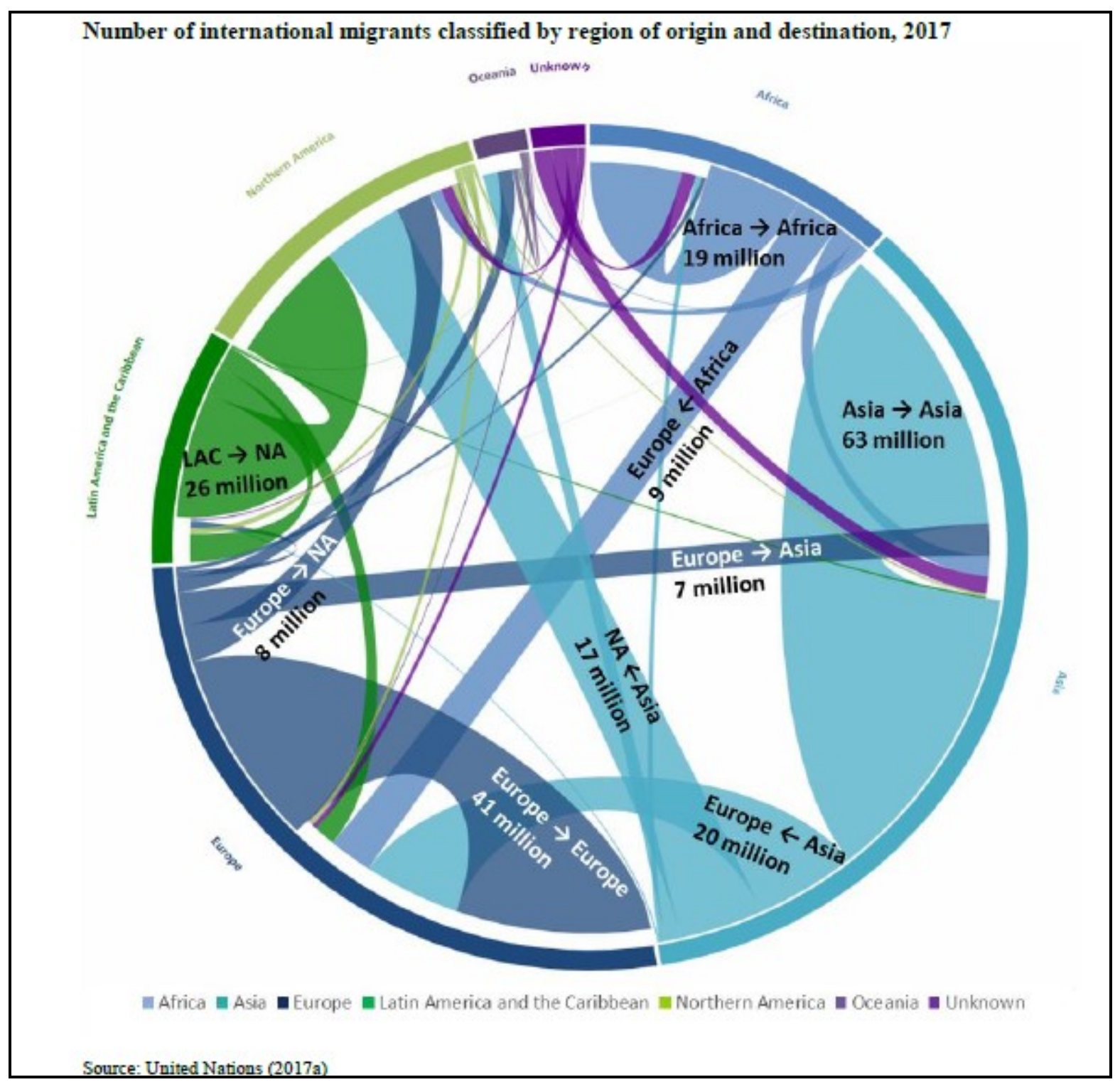

Fonte: United States. International Migration Report 2017: Highlights. ST/ESA/SER.A/404. New York, 2017.

Os veículos de informação contribuem, portanto, para construção de regimes de visibilidade: "A ideia principal dessa expressão é a de que existe uma espécie de protocolo, de cartilha de procedimentos regulares, que estabelecem socialmente aquilo que deve ser visto, as condições e os valores que devem ser 
julgados" (GOMES, 2013, p.51). Esses regimes de visibilidade são, ainda segundo Gomes “(...) modulados pela espacialidade, ou seja, o ‘que' ver e 'como' ver são completamente tributários de 'onde' ver (2013, p.53).

Ao fazer o exercício de pesquisar palavras-chave na plataforma de busca Google foram escolhidas: "migração", "mapas" e "Europa". Os primeiros resultados retornam imagens de mapas e infográficos, aspecto esse que não se verificou quando feito o mesmo exercício para os outros fluxos migratórios assinalados na figura 4. Chama atenção, para além dos números, que os dois primeiros resultados de busca são noticias, que em sua chamada já caracterizam o fenômeno como crise e antecipam a intenção de fazer o leitor ficar a par da sua conjuntura.

O material desenvolvido pelas mídias de grande circulação tende a ser mais detalhista em suas representações quando comparado ao material base da Frontex. Isso se deve à preocupação subjacente dos leitores de estar "antenados" as atualidades numa lógica de consumo da informação. Dito de outro modo, o importante é estar bem informado sobre algo e não o contexto retratado em si. De modo geral, essas noticias costumam seguir uma tônica individualista e consumista da informação: “o que você precisa saber para estar antenado sobre o assunto", mas com o distanciamento necessário para que o leitor/expectador não precise se colocar no lugar do outro ou exercite empatia ao contexto colocado em tela.

Vidas humanas em fluxo são convertidas em formas homogêneas e invisíveis, por meio da linguagem matemática, em mapas e gráficos. A ideia é que as pessoas saiam egocentricamente preparadas para uma "prova de atualidades", mas, que não necessariamente desenvolva crítica ou compromisso coletivo com o que se pauta. Entende-se aqui como crítica a capacidade de examinar as bases de nossos conhecimentos para a formulação de decisões, de examinar a relação entre o poder e o conhecimento a partir de uma perspectiva 
histórica e, por vezes, resistir, desafiar e descartar nossas categorias de pensamento (CRAMPTON, J.W; KRYGIER, J, 2008).

Por que, aparentemente, existiria um interesse pelos órgãos oficiais da União Europeia e grande mídia de traduzir e decodificar os números dos fluxos migratórios em mapas de assimilação rápida o suficiente, para que o leitor se sinta bem informado sobre aquele fenômeno migratório? Porque possuem a função de interpelar os sujeitos a construção de determinados entendimentos sobre o real, tais como a noção de ameaça ou crise. A interpelação "é uma ilustração, um exemplo adaptado a um modo específico de exposição, suficientemente 'concreta' para ser reconhecida, mas abstrata o bastante para ser pensável e pensada, dando origem a um conhecimento" (PÊCHEUX, 1996 p. 149).

Consolidar a impressão de uma Europa tensionada pelas mais diversas frentes migratórias fixa, de forma subliminar no imaginário popular, a imagem de algo a ser monitorado e devidamente controlado. Para Bakhtin (1992) "o ser, refletido no signo, não apenas nele se reflete, mas também se refrata." Assim se oculta/refrata outros aspectos que são desviantes do discurso que se pretende comunicar sobre aqueles fluxos. E nesse sentido quebra-se ou desvia-se a atenção para determinados aspectos em detrimento de outros. Lacoste defendia que historicamente a linguagem cartográfica atendeu a tais propósitos:

É sobre a carta que devem ser colocadas todas as informações necessárias para a elaboração de táticas e estratégias. Tal formalização do espaço, que é a carta, não é nem gratuita, nem desinteressada: meio de dominação indispensável, de domínio do espaço, a carta foi, de início criada por oficiais e para os oficiais. A produção de uma carta, isto é, a conversão de um concreto mal conhecido em uma representação abstrata, eficaz, confiável, é uma operação difícil, longa e onerosa, que só pode ser realizada pelo aparelho de Estado e para ele. A confecção de uma carta implica num certo domínio político e matemático do espaço representado, e é um instrumento de poder sobre esse espaço e sobre as pessoas que ali vivem" (LACOSTE, 1997 p.23).

Quais sentimentos um mapa político em pequena escala pode despertar? Yves Lacoste (1996) aponta que a aparente inutilidade, repetição ou permanência 
no discurso geográfico se constitui elemento extremamente poderoso para homogeneização.

Tais marcadores, de descontrole e ameaça, criam o ambiente propicio para o crescimento da extrema direita na Europa verificado nos últimos anos. Isso por que este segmento se posiciona contra essas tendências de globalização por remete-las a um sentimento de perda da identidade nacional. Questões como o Brexit, referendo realizado no Reino Unido que decidiu por sua retirada da União Europeia, estão ligados a esse crescimento do sentimento anti-imigração, antiglobalização e ao eurocentrismo.

Conforme Žižek (2011) chama atenção, não devemos nos esquecer de que a política contra a imigração não está vinculada diretamente ao capitalismo nem aos interesses do capital. Ao contrário, a livre circulação de mão de obra é do interesse do grande capital, já que a mão de obra imigrante barata tende a pressionar os trabalhadores europeus a aceitar salários mais baixos e nesse sentido a resistência contra os imigrantes é, em primeiro lugar, uma reação defensiva espontânea da classe trabalhadora local, que percebe o trabalhador imigrante como um novo tipo de fura-greve e, dessa forma, aliado do capital.

\section{OUTRAS FORMAS DE REPRESENTAÇÃO: A POSSIBILIDADE DE NOVOS}

\section{OLHARES}

Como o ensino de Geografia pode atuar sobre um fenômeno tão midiatizado e explorar determinadas facetas que se desviem dos marcadores fixados no senso comum sobre tais fluxos, que homogeneízam a analise espacial? Como poderia sair da mera informação fragmentada e fragilmente situada sobre dado fenômeno, demanda per si já atendida pelo jornalismo? Como se apropriar destes fluxos, enquanto práticas espaciais, que exercitam um olhar outro sobre o espaço geográfico e suas dinâmicas? Como transitar do caráter informativo para o formativo, de modo a permitir aos sujeitos construir raciocínios 
geográficos para compreensão das condicionantes e espacialidades de dado fenômeno? E, por fim, como representar esses raciocínios numa lógica que, se desvie do controle técnico que monopoliza a narrativa e dispõe dos códigos de comunicação para representações outras que sejam inteligíveis, permitam o exercício da crítica além de novos conhecimentos acerca do fenômeno espacial que se analisa?

A leitura desconstrucionista do mapa (HARLEY,1989) é um fundamento básico da chamada Cartografia Geográfica Crítica, pois rompe com a visão que relaciona o mapa diretamente ao positivismo e desmitifica a verdade absoluta que supostamente carrega. A teoria crítica do mapa chama atenção para a textualidade do mapa, sua subjetividade e retórica pois, como produto intelectual, o mapa carrega a intensionalidade do seu autor.

A concepção desconstrutivista do mapa “Deconstructing the map" (1989) de Harley foi um dos primeiros a vislumbrar e o primeiro a denunciar de forma ampla e fundamentada a absoluta ausência de neutralidade dos mapas e a incongruência entre realidade e representação neles contida. Na sua concepção, que deu origem a toda uma linha teórica na análise da Cartografia, os mapas são textos, não apenas pela presença de elementos linguísticos, mas principalmente pelo ato de construção que os concebe.

No contexto como o atual, conhecer os territórios e suas geografias é, sem dúvida, aspecto fundamental para a ação. Nestes termos, as teorias que se desenvolvem para explicar a atual organização espacial do mundo contemporâneo, procuram mapear, ainda que mental, ou descritivamente, fixos e fluxos. Hoje os fixos são cada vez mais artificiais e mais fixos, fixados ao solo; os fluxos são cada vez mais diversos, mais amplos, mais numerosos e mais rápidos (SANTOS, 1994). 
Segundo Milton Santos (1994) o espaço é uma reunião dialética desses fixos e fluxos, aspecto que configura seu caráter extremamente dinâmico, ao passo que as representações que fazemos dele são estáticas. A complexidade das novas dinâmicas espaciais obrigam a Geografia a encontrar formas apropriadas de representação. As dinâmicas sociais não estão submetidas a formas rígidas, assim como as configurações socioespaciais a elas associadas. Como espacializar os fluxos humanos, tendo em vista essa premissa, sem necessariamente incorrer às interpelações fixadas no senso comum pelos veículos de comunicação em massa sobre tais fluxos? O uso dos coremas pode se constituir uma possibilidade.

Coremas seriam representações cartográficas, teóricas, formalizadas e abstratas do real que buscam identificar estruturas elementares de uma dada organização espacial (BRUNET, 2001). Ela escapa às regras clássicas dos mapas, pois seu objetivo não é de ser fiel à realidade geográfica, nem de ser minuciosa quanto à representação dos fenômenos. Não é também, segundo Brunet (2001), nem um croqui, nem um esquema.

As composições coremáticas permitem construir representações que fogem ao padrão de mapa cartográfico ao sistematizar um mapa-modelo. Eles são registros de interpretações qualitativas do espaço. Ao primeiro olhar podem até confundir o leitor devido à variabilidade de formas. Mas, Dutenkefer (2010) expõe que os mapa-modelos "são mapas a serem lidos e não vistos". Desta maneira, o processo de criação dos coremas envolve diversas reflexões sobre a dinâmica espacial.

O trabalho de Brunet reavivou o debate sobre o uso de modelos cartográficos, que permitiriam "ler, sob a complexidade da representação, a simplicidade dos fenômenos envolvidos, a expressão de leis, mecanismos e comportamentos" (BRUNET, 2001, p. 254). Essa abordagem tem suscitado as 
críticas daqueles que consideram a coremática viciada pelo determinismo e inclinada a uma "hipersimplificação" inaceitável da complexidade da realidade territorial, articulada demais para ser explicada pelos modelos. O autor foi interpretado algumas vezes como racionalista Brunet por buscar: "descobrir a ordem subjacente à aparente desordem" (BRUNET, 2001, p. 189) ou por afirmar que "há uma ordem no mundo, basta encontrá-la" (BRUNET, DOLLFUS, 1990, p. 76).

Mas, em essência, a acusação parece ser construída sobre um malentendido: na tradição geográfica, a expressão "modelo" repousa sobre uma visão fundamental de um tipo determinista que considera o território como um sistema mecânico. Alfred Weber e Walter Christaller desenvolveram modelos nessa perspectiva. Na coremática, por outro lado, a expressão "modelo" não tem uma disposição normativa e deve ser entendida como uma representação destinada a descrever uma situação específica e não, como o significado clássico sugeriria, um esquema "para a compreensão e apresentação de leis, desenvolvimentos, relações e estruturas" (RUOCCO, 1988, p. 530).

Os coremas nascem da percepção de que pode ser profícuo relativizar as formas rígidas de representação espacial. O modelo gráfico proposto por Brunet (2001) surge da combinação de sete "lógicas sociais de controle e dominação do espaço" e quatro figuras geométricas. As lógicas sociais são pautadas na influência e poder dos atores espaciais e são reconhecidas como malha, ligação, contato, gravitação, tropismo, dinâmica territorial e hierarquia. Já as figuras geométricas utilizadas são representadas pela linha, o ponto, a área e a rede. A figura 05 demonstra a interação dessas sete lógicas sociais de controle e dominação do espaço com as quatro figuras geométricas se produzem vinte e oito estruturas espaciais ou coremas.

Figura 05- Proposições coremáticas de R. Brunet. 


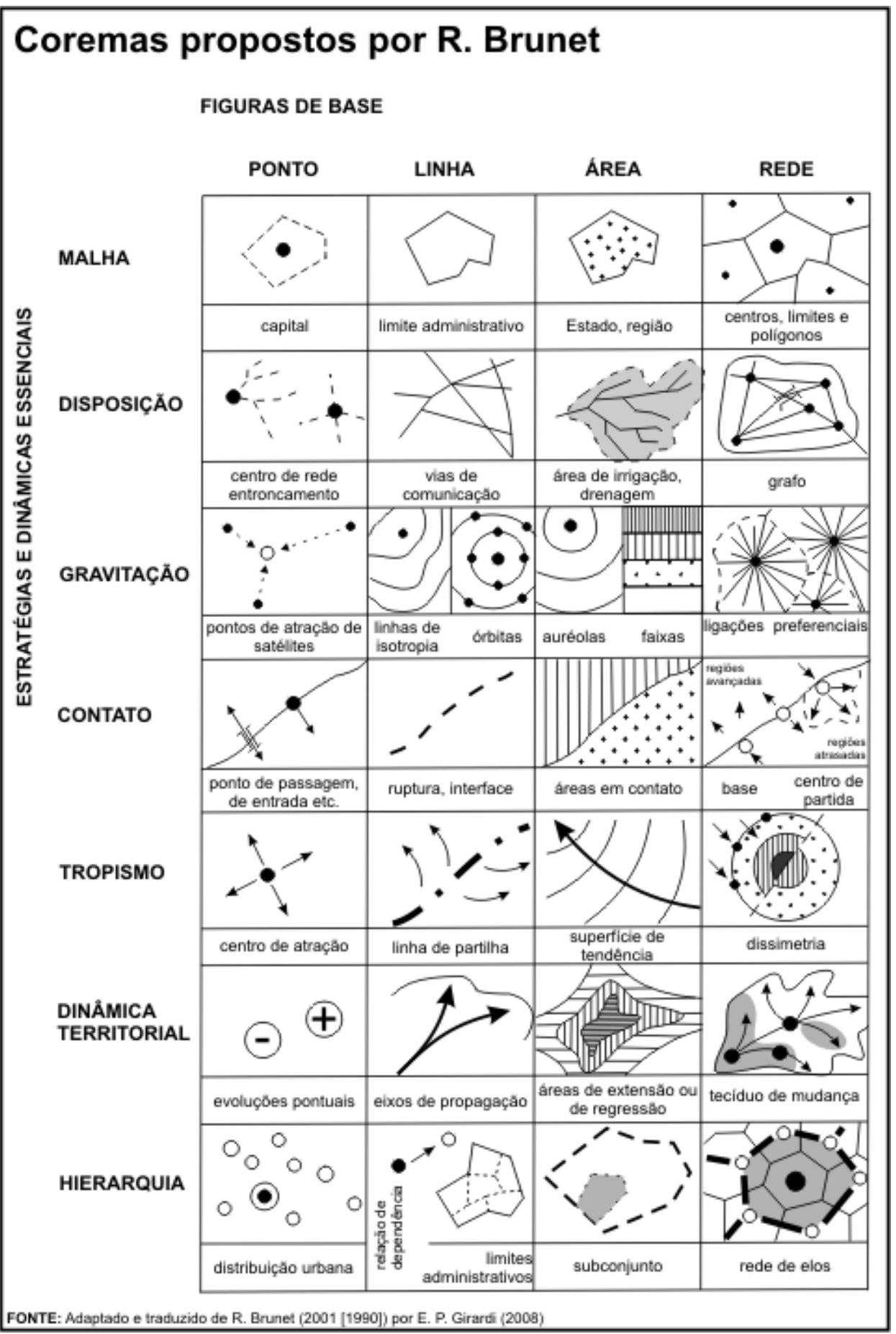

Fonte: (GIRARDI, 2015. p. 75).

Os coremas se baseiam, portanto, em figuras simples e em algumas regras fundamentais. Sete figuras são suficientes para escrever os modelos que representam os coremas e seus conjuntos: a área, o ponto, a linha (que liga, que coloca em contato ou que separa respectivamente) que podem consubstanciar fluxos, passagem, variação, polarização etc). Todo o resto depende de um incessante trabalho de hipóteses, de análises e verificações por isso seu caráter didático e autônomo. 
A composição de mapas-modelo, com uso de coremas, no processo de ensino de Geografia pode ter potencial no estudo de fluxos humanos a medida que: i- fornece aos sujeitos os códigos para construção de raciocínios próprios acerca da leitura do espaço (o que romperia com o domínio do controle técnico) ii- permite trabalhar com inúmeras variáveis e chaves de leitura do espaço (o que pode minimizar o ocultamento de contradições) iii-pode subsidiar novas leituras para além das imagens que se fixam como marcadores no senso comum iv- possibilita o rompimento com o nível informativo dos fenômenos e pode caminhar assim para o nível formativo dos estudos em Geografia pela metodologia de aprendizagem por investigação (em variadas fontes).

Figura 06- As três fronteiras da Europa.

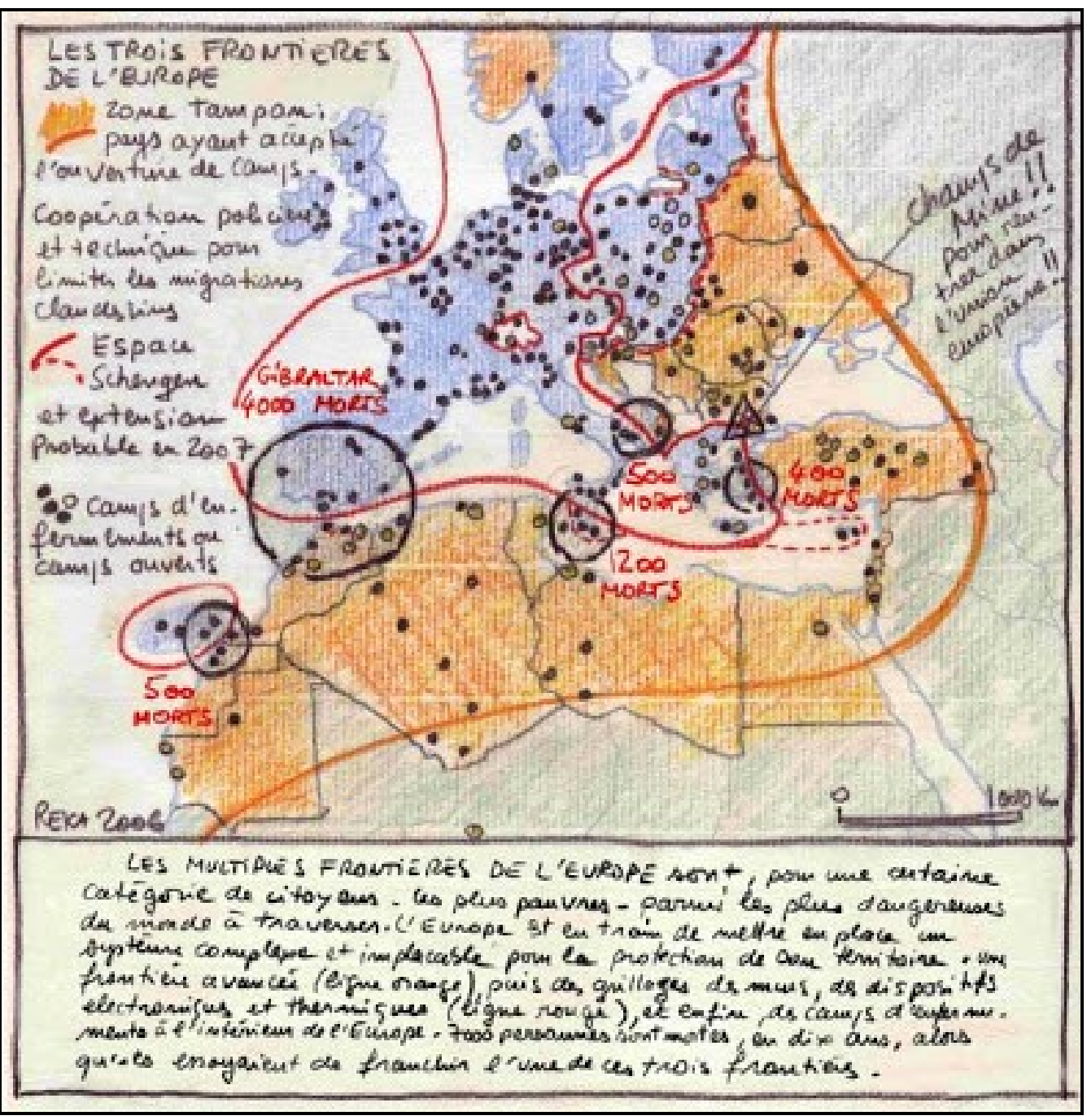

Fonte: Disponível em: http://fieldsofexploration.blogspot.com/2012/02/lecture-with-philipperecacewicz.html Acessado em: 09/06/2019. 
No âmbito da análise dos fluxos humanos, inclusive no âmbito Europeu já existem iniciativas de pesquisadores que se apropriam da premissa dos coremas para uma analise multifacetada de tais fenômenos. Como os mapas-modelos de Philippe Rekacewicz (figura 06), geografo francês que se dedica ao estudo da percepção e representação de fronteiras.

O caráter polissêmico da coremática implica nas mais variadas possibilidades de representação e análise do espaço, pelas quais acreditamos ser possível analisar de maneira adequada os sistemas de objetos e os sistemas de ações, bem como a interação entre eles, a partir da identificação dessas estruturas elementares pelas quais passa o domínio do espaço: os coremas. As chamadas "três fronteiras da Europa" e os centros de triagem se constituem estruturas fundamentais para compreensão do fenômeno migratório em foco. Aspectos estes que Rekacewicz (2012) procura chamar atenção com suas proposições coremáticas (figura 07) quando também representa a origem dos fluxos e os óbitos na fronteira.

Figura 07- Migração para o continente europeu.

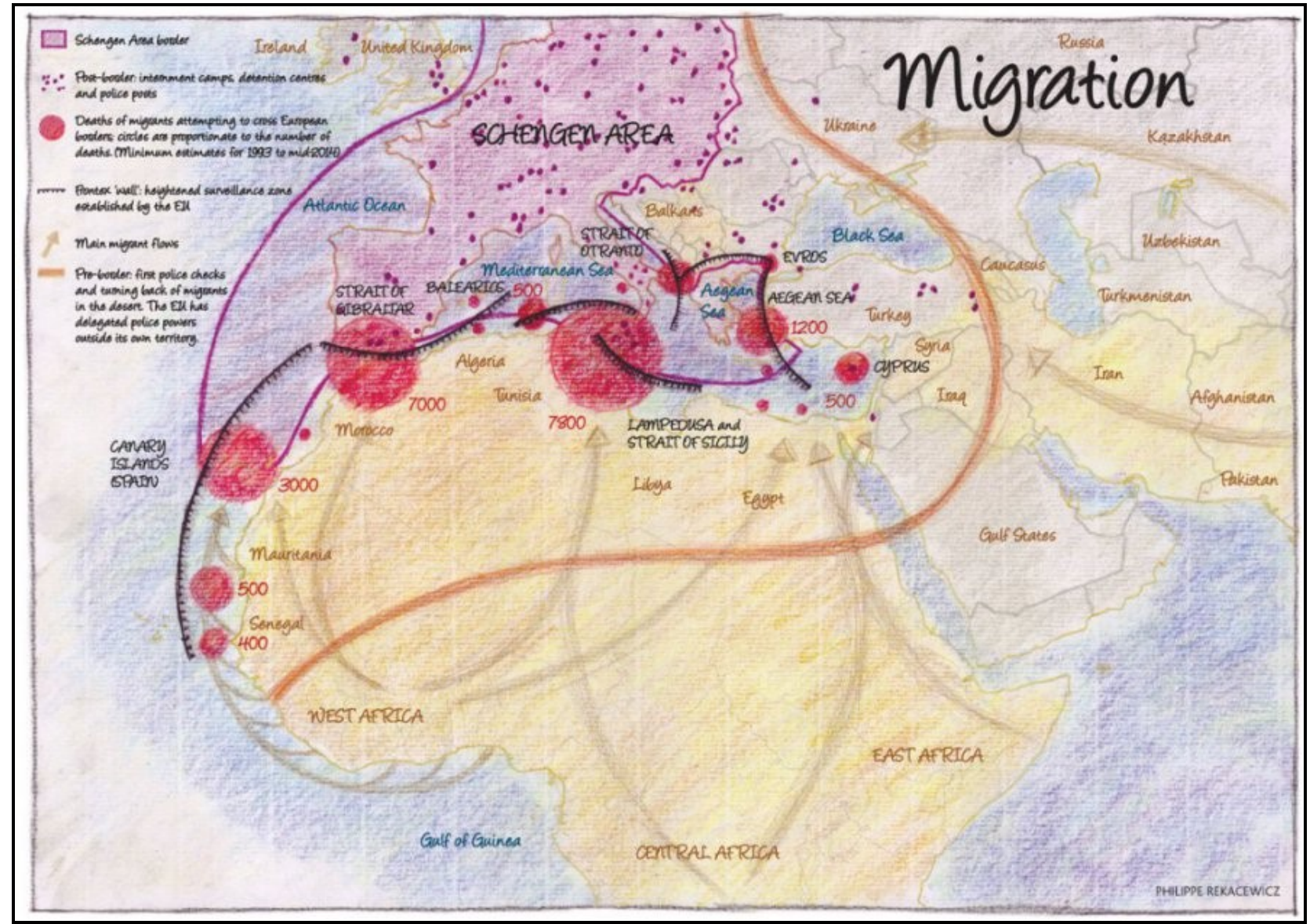

Fonte: Disponível em : http://clioweb.canalblog.com/archives/2013/10/15/28225657.html Acessado em: 09/06/2019 
Contudo, esta prática só é possível se admitimos que o mapa, como fonte de conhecimento, portador de textualidade e retórica, e, portanto, poder, é um território imaterial que, por representar imaterialidade e materialidade, contribui para a formação de territórios por meio da apropriação, influência ou domínio do espaço (GIRARDI, 2015). É uma proposição que tem potencial por agrupar teoria, técnica e método, o que possibilita leituras qualificadas da realidade com auxílio do mapa.

\section{CONTORNOS FINAIS}

A coremática pode fornecer ferramentas preciosas para compreender e figurar o Mundo: sua utilização pode conduzir os alunos a questionar, a emitir hipóteses e a compreender a organização espacial de um lugar quando associada aos princípios da aprendizagem por investigação (CACHINHO, 2000). Além do desenvolvimento do espírito de análise necessário a práticas de ensino e aprendizagem que busquem se distanciar de possíveis marcadores que fixem imagens da realidade que se distanciem da complexidade do real.

Não incorremos na inocência de acreditar que o uso de coremas por si só já garantiria aos estudantes a construção de compreensões que se distanciem ou sejam imunes aos interesses de setores organizados que os interpelam diariamente. Mas se podem se constituir uma ferramenta de educação alternativa para reflexão sobre/no espaço da complexidade das relações sobre os fixos e fluxos que compõem a tessitura socioespacial bem como das impressões e representações que delas nascem e suas funcionalidades.

Do mesmo modo como CRAMPTON, J; W. KRYGIER, J (2008) reconhecem os limites de se propor uma cartografia "indisciplinada" ou "popular", uma vez que embora o efetivo negócio da confecção de mapas, do levantamento de dados espaciais e seu mapeamento, esteja gradativamente saindo das mãos dos especialistas por meio dos softwares livres, é igualmente verdade que o 
mapeamento livre somente é eficaz quando pessoas têm acesso à tecnologia, seja ela a internet, um computador e talvez com importância ainda maior, o conhecimento para usá-la. A distribuição desses recursos é espacialmente desigual no Brasil e está longe de ser uma realidade nas escolas publicas brasileiras.

Por tudo isso, o que se propõe aqui pela linguagem coremática é ampliar as possibilidades, não só da produção de mapas, mas, sobretudo de sua leitura e sistematização. Aponta-se como caminho a prática da aprendizagem por investigação, devidamente mediada pelo professor. O uso de coremas pode fornecer operacionalidade nesse sentido, uma vez que tende a fortalecer a autonomia dos sujeitos além de favorecer a diversidade interpretativa do modo dinâmico, tenso e contraditório que a humanidade em fluxo se (re)organiza no espaço.

\section{REFERÊNCIAS}

ALTHUSSER, L. Ideologia e Aparelhos Ideológicos do Estado. In: ZIZEK, S. Um mapa da ideologia. Contraponto editora, Rio de Janeiro, RJ, 1996.

BAKHTIN, M. Marxismo e filosofia da linguagem . Hucitec, São Paulo, SP, 6a edição, 1992.

BROTTON, J. Uma História do Mundo em Doze Mapas. Rio de Janeiro: Zahar, 2014.

BRUNET, R. Le déchiffrement du monde: théorie et pratique de la géographie. França/Paris: Belin, 2001.

BRUNET, R. DOLLFUS O. Géographie Universelle, I, Mondes nouveaux, Parigi, Belin/Reclus, 1990.

CACHINHO, H. Geografia escolar: orientação teórica e praxis didáctica. Inforgeo, 15, Lisboa, Edições Colibri, 2000, p. 69-90.

CRAMPTON, J.W. KRYGIER, J. Uma introdução à cartografia crítica. ACME: An International E-Journal for Critical Geographies, Volume 4, Issue 1.Tradução de Carolina Apolinário de Souza in Cartografias sociais e território / Henri Acselrad (organizador). Rio de Janeiro: Universidade Federal do Rio de Janeiro, Instituto de Pesquisa e Planejamento Urbano e Regional, 2008. 168 p. 
DEL GAUDIO, R. S. O mapa enquanto discurso e o discurso do mapa - algumas questões. Rev. Ensaio | Belo Horizonte | v.05 | n.02 | p.129-145 | outubro | 2003.

DUTENKEFER, E. Representação do espaço geográfico: mapas dasimétricos, anamorfoses e modelização gráfica. Dissertação (Mestrado em Geografia). São Paulo: Faculdade de Filosofia, Letras e Ciências Humanas (Universidade de São Paulo), 2010.

FOUREZ, G. Cómo se elabora el conocimiento. Madrid: Narcea, 2008.

GIRARDI, L. Estruturas e dinâmicas espaciais da organização da internet no território brasileiro, Confins [Online], 23 | 2015 Acessado em 19 abril 2018 Disponível em : http://journals.openedition.org/confins/9976

GOMES, PAULO C.C. O lugar do olhar. Rio de Janeiro: Bertrand Brasil, 2013.

HARLEY, J. B. Deconstructing the map. Cartographica. v.26, n.2. Toronto: University of Toronto Press, 1989. p.1-20.

JOLY, F. A Cartografia. Papirus Editora, Campinas, SP, 1990.

LACOSTE, Y. A Geografia - isso serve, em primeiro lugar, para fazer a guerra. Papirus Editora, Campinas, SP, 4a edição, 1997.

LEFEBVRE, H. Espacio y política. 62.ed. Barcelona: Península, 1976.

MONMONIER, Mark. How to lie with maps. Chicago: University Of Chicago Press, 1996.

PÊCHEUX, M. O mecanismo do (des)conhecimento ideológic". In: ZIZEK, S. Um mapa da ideologia. Contraponto Editora, Rio De Janeiro, RJ, 1996.

PICKLES, J. A History of Spaces. Cartographic Reason, Mapping and the Geo-Coded World. London: Routledge. 2004.

REKACEWICZ, P. L'Europe et ses frontières paradoxales, Le Monde diplomatique, 27 novembre, 2006 Disponível em: :https://blog.mondediplo.net/2006-11-27-L-Europe-etses-frontieres-paradoxales Acessado em: 09/06/2019

SANTOS, M. A Natureza do Espaço: Técnica e Tempo, Razão e Emoção / Milton Santos. - 4. ed. 2. reimpr. - São Paulo: Editora da Universidade de São Paulo, 2006.

SANTOS, M. Técnica, espaço, tempo: globalização e meio técnico-científico informacional. São Paulo: HUCITEC, 1994.

RUOCCO D. Glossario Geografico Internazionale, Napoli, Unione Geografica. Internazionale/ Istituto Geografico Italiano, 1988. 
THERBORN, G. The Ideology of Power and the Power of Ideology. London: 1980.

ŽIŽEK, S. Primeiro como tragédia, depois como farsa. Tradução: Maria Beatriz de Medina. - São Paulo : Boitempo, 2011.

\footnotetext{
' Para mais informações consultar: KOENIG, Nicole. The EU'S external migration policy: towards winwin-win. POLICY PAPER, APRIL 2017.

ii Informações do site da agencia: https://frontex.europa.eu/pt/sobre-nos/o-que-e-a-frontex-/ Acessado em 02/09/2019.

iii México- USA 12,275,876,2) Russia- Ucrania 2,276,756,3) Ucrania - Russia 3,269,992 4) India- Emirados Arabes Unidos 3,184,017 5) Bangladesh- India 3,171,022 6) Siria - Turquia, 2,766,494 Resultados de pesquisa a partir da plataforma Google em busca realizada em 19/01/2019.
} 